\title{
MIRADAS SOBRE COMPOSTELA EN LAS OBRAS DE GONZALO TORRENTE BALLESTER
}

\author{
Carmen BECERRA SUÁREZ \\ Universidad de Vigo \\ cbecerra@uvigo.es
}

$\mathrm{N}$

o es tan común, como en principio pudiera parecer, que el territorio donde se nace se convierta en el referente espacial o en el imaginario cultural de los mundos literarios de un autor; pero en el caso de Gonzalo Torrente Ballester la presencia de lo gallego en sus obras supone casi una constante y la ausencia se revela como un filtro desde el que se ve y se crea la realidad. Y no estoy sólo aludiendo a rasgos de tipo formal, es decir, léxico, sintaxis, ritmo..., sino sobre todo a contenidos, temas, personajes, recursos retóricos o maneras de situarse y ver el mundo. El lector que se aproxime a las creaciones literarias de este autor comprobará, por ejemplo, que las páginas de muchas de sus novelas albergan ciudades y pueblos gallegos: el valle de Serantes, Ferrol, Bueu, Santiago de Compostela, Pontevedra y Orense son algunos de los lugares por los que el narrador transita con más calma; y en ellos identificamos, con facilidad, sus singulares características en el marco de un territorio común: «Galicia está en mis novelas porque el mayor acopio de mi experiencia es gallego [...]. Lo gallego es lo mío, y aunque podría repetir que nada humano me es ajeno, lo que me llega más al corazón, lo que entiendo mejor es lo gallego» (Torrente Ballester, 1998) ${ }^{1}$.

El examen, ni siquiera detenido, de sus obras pone de manifiesto su esencial galleguidad. Es la realidad gallega, su historia y sus gentes, sus costumbres, ritos y supersticiones, el paisaje del noroeste peninsular lo que encontramos en sus páginas. Pero, el asunto, abordable desde perspectivas y niveles diversos, es lo suficientemente amplio para que ahora lo aconsejable sea realizar sólo una aproximación parcial, razón por la cual, en este artículo, me centraré exclusivamente en la presencia de la ciudad compostelana en sus obras.

A nadie que conozca la trayectoria biográfica de Torrente Ballester sorprenderá que algunas de sus obras remitan a un espacio extratextual llamado Santiago de Compostela. Si algunas ciudades marcaron de forma indeleble el espíritu del escritor gallego, una de ellas, y no la de menor importancia, fue Santiago. No son pocas las ocasiones en las que el autor lo confiesa: «Una ciudad que aprendí a amar, a la que vuelvo con emoción, en la que me siento feliz» (1983: 298). Santiago ejerce sobre él

\footnotetext{
${ }^{1}$ Frases entresacadas de «Entrevista» a Gonzalo Torrente Ballester en el periódico La voz de Galicia (22 de mayo de 1998).
} 
una fuerte fascinación y su recuerdo se traduce siempre con cierto aire de nostalgia. Así, por ejemplo, en el artículo que dedica a la biblioteca de la Universidad, el lector advierte con claridad ese estado anímico en el Yo que enuncia:

La Biblioteca América, más reducida que la general, aprovechaba mejor el calor de los grandes radiadores anticuados, y se podía estar en ella, sentado, un par de horas. Mi mesa se situaba al fondo, a la izquierda, al lado de una ventana abierta sobre la cornisa exterior del edificio. Encima de la piedra había crecido el musgo, y cuando le daba el sol, su color era bellísimo, un verde terciopelo para mí inolvidable [...]. Más de una vez escribí que esos tres años pasados en Compostela, fundamentalmente en sus bibliotecas, fueron muy importantes, por no decir decisivos, en mi formación. Cuando entré allí la primera vez, pensé que tenía ante mí lo necesario para completar mi carrera, entonces incipiente, de profesor. La delicada, compleja, indescriptible operación que hizo de mí un escritor, transcurrió allí dentro, entre libros de monjes y libros de legados americanos: fue una especie de deslizamiento imperceptible, que me llevó de la Ciencia a la Poesía y que me instaló en ésta definitivamente... Allí, en aquellos salones vacíos, aprendí, con mi sangre, lo que es la tradición cultural, en qué consiste el mundo del Espíritu al que pertenezco (Torrente Ballester, 1980: 170).

Los amores entre Gonzalo Torrente y Santiago de Compostela comenzaron muy pronto, jalonados de ausencias, de idas y venidas, y mantenidos con pasión avivada por el recuerdo; no se interrumpieron nunca y perduran incluso después de su marcha definitiva ${ }^{2}$. Aunque el camino francés es el más antiguo, son muchos los caminos que conducen a Compostela y Gonzalo Torrente los recorrió todos. El primero de estos caminos, muy común entre los jóvenes en formación, sobre todo gallegos, es el recorrido por un estudiante.

\section{Primera mirada: La mirada del estudiante}

En 1926, un joven ferrolano llamado Gonzalo Torrente se instala en Santiago para preparar su acceso a la Universidad. Un año más tarde, la familia se traslada a Oviedo, destino temporal de su padre, y Gonzalo comienza sus estudios universitarios en la Facultad de Derecho de la Universidad ovetense. Un nuevo traslado paterno, en 1928, le lleva a Vigo, y desde allí se desplaza con frecuencia a Madrid para continuar sus estudios. En 1931, su padre es destinado a Bueu, Gonzalo se matricula en la Universidad de Santiago, pero ahora en la Facultad de Filosofía y Letras. En 1933, ya casado, fija su residencia en Ferrol, malvive con el dinero que, por dar clases de Gramática, le pagan en una academia de la ciudad y continúa sus estudios en la Universidad compostelana para terminar la carrera iniciada dos años antes. Es un estudiante por libre que se acerca a Santiago, de vez en cuando, como turista o como estudiante dispuesto a rendir exámenes. En 1935, ya padre de dos hijos, se licencia en Historia.

Fueron años de miradas inaugurales a muy diversas geografías y ambientes. De ellos quedaron conocimientos, amigos, modos de vida y algunos paisajes atrapados por la retina de un visitante atento, curioso y ávido por saber y entender. Por entonces, la mirada de Gonzalo, probablemente como la de la mayoría de los jóvenes, estaba más interesada por el presente, por las personas y su manera de vivir,

\footnotetext{
${ }^{2}$ Su voluntad, por escrito en su testamento, de crear la Fundación Gonzalo Torrente Ballester en Santiago, legando la totalidad de su legado: su biblioteca, su archivo documental y sonoro, sus herramientas de escritura, el epistolario, los muebles y enseres que le rodeaban en su lugar de trabajo, sus colecciones, premios... así lo acredita.
} 
que por aquello que originaba su existencia cotidiana, aunque no sólo; pero pronto esa mirada modificaría su dirección emprendiendo un segundo camino.

\section{Segunda mirada: La mirada del profesor}

En mayo de 1936, gana por oposición una plaza de Profesor Auxiliar de Historia en la Universidad compostelana que, dos meses más tarde, le concede una beca para iniciar los trabajos de documentación conducentes a la elaboración de su tesis doctoral: el 13 de julio se desplaza a París. El estallido de la Guerra Civil trastoca los planes de este aspirante a doctor, como los de todos los españoles. Acabada la guerra, se incorpora a su puesto de Profesor en la Universidad y se instala en Santiago (en la Rúa Cardenal Payá), en donde nace el cuarto de sus hijos. El curso siguiente, 1940, gana la oposición a cátedras de Instituto en la disciplina de Lengua y Literatura: su plaza era el Instituto de Ávila, pero consigue una comisión de servicios con destino en el Instituto Rosalía de Castro de Santiago de Compostela.

Durante estos años, la mirada del joven profesor sobre Santiago ha cambiado: ahora sus ojos recorren la arquitectura, se interesan por el pasado de la ciudad y sus leyendas, por su historia, gozan del color que arranca el sol de sus piedras mojadas y se deleitan con el olor a invierno. La mirada de Torrente se empapa de Compostela y el placer de los sentidos se asocia para siempre con el conocimiento profundo del ser de la ciudad. Hace dos años que ha publicado su primera obra, una pieza teatral titulada El viaje del joven Tobías (1938). Ha comenzado ya esa «especie de deslizamiento imperceptible», que le llevó «de la Ciencia a la Poesía» y le instaló en ésta definitivamente.

\section{Tercera mirada: La mirada del escritor}

En 1942 abandona Santiago y, de nuevo en comisión de servicios, ocupa la cátedra del Instituto Concepción Arenal de Ferrol; en él permanece cinco años hasta que, en 1947, acepta un puesto de profesor de Historia en la Escuela de Guerra Naval de Madrid³. Por tanto, el verano de 1942 es el último que contempla a Gonzalo Torrente como vecino de la ciudad de Santiago.

La literatura dibuja geografías, hasta el punto de que nuestro conocimiento de los espacios se produce en innumerables ocasiones gracias a ella. A lo largo de la extensa trayectoria literaria de Gonzalo Torrente Ballester se yerguen reiteradamente las voces de la memoria que construyen una realidad evocada, también soñada y añorada: la fantástica realidad de Galicia que conforma la urdimbre afectiva del hombre y se transforma, por mediación del escritor, en un universo con señas de identidad propias, inclinado, desde siempre, a la maravilla y el prodigio. Santiago es una de esas realidades evocadas y, en ocasiones, desde la distancia, ya no es la ciudad el objeto de su contemplación sino que es ella quien contempla e interpela al hombre que la mantiene en su memoria. Instalada en su interior sale a la luz transformada gracias al arte de la palabra.

\footnotetext{
${ }^{3}$ Este es el recorrido de Torrente Ballester desde entonces: 1947-1962 Madrid; 1964-66 Pontevedra; 1966-71 EEUU; 1971 Orcasitas y EEUU; 1973-75 Vigo; 1975 Salamanca.
} 
Son cuatro los libros que el autor dedicó a esta ciudad gallega: dos novelas, Fragmentos de Apocalipsis y La muerte del decano, y dos obras, escritas por encargo, de difícil clasificación genérica: Compostela y su ángel ${ }^{4}$, y Santiago de Rosalía de Castro. Apuntes sobre la vida en Compostela en tiempos de Rosalía de Castro.

Compostela y su ángel, escrito en 1947, fue publicado por primera vez en 1948 con motivo de la celebración del año santo compostelano. Se trataba de una edición lujosa e ilustrada que se agotó pronto, para luego dormir, durante décadas, en el olvido de crítica y lectores. La editorial Destino lo rescató publicándolo en edición de bolsillo, en 1984. Las tres primeras páginas, tituladas «Introducción a Compostela», escritas y publicadas en 1941 en un periódico madrileño, no dejan lugar a duda respecto a la unidad de estilo del autor:

Compostela se hace en torno a la campana. La campana lo va creando día a día, siglo a siglo, sin más que dar las horas. Y la niebla es el caos de donde la campana va sacando las cosas. Primero su propio bronce sonoro, la torre de donde pende, y su nombre. Después, las piedras labradas, las bóvedas, las cresterías, las fachadas y los patios. Por último, las callejuelas y las plazas, y los santos en sus hornacinas [...]. Cuando la niebla sumerge la ciudad, todo vuelve al estado primitivo e informe y no quedan sino la niebla y las campanas. Las casas se desvanecen, disolviéndose su ser en cierta involución que las hace fantasmales [...]. Da la impresión de que un poco más de niebla dejará de la ciudad sólo el recuerdo [...]. El ser de Compostela es este hacerse y deshacerse en juego interminable (1984: 17).

En el prólogo, que el autor escribe para esta reedición en Destino, declara una vez más su amor a la ciudad y la deuda con ella contraída:

De mi entusiasmo antiguo por Compostela queda hoy, muy firme, mi admiración estética, pero también mi amor a una realidad que va más allá del arte, de la que me he nutrido mucho más de lo que a primera vista parece. No exageraría demasiado si dijera que, por encima del tiempo, y contradiciéndome, la expresión del sentido del humor la aprendí después de haber escuchado esa broma silenciosa que se traen, hecha de gestos y sonrisas, las figuras del Pórtico (1984: 13).

... deuda de la que el Apéndice de esa edición, titulado «Mi visión de la ciudad en 1977», supone una evidente prueba, porque esa «visión» no es otra cosa que unas páginas de su novela Fragmentos de Apocalipsis, novela que el autor dedica a Santiago y a la que volveremos con más detalle más adelante ${ }^{5}$.

Gonzalo Torrente sumerge al lector con este libro en la Compostela más antigua, rica en mitos y leyendas. Con su singular estilo, en el que fantasía y realidad conforman un todo indisoluble, el autor proporciona una fascinante historia de la ciudad, desde su fundación por Alfonso el Casto y el obispo Teodomiro, en la que encontramos tanto el origen de la leyenda del sepulcro del Apóstol como las crónicas del Camino de Santiago que la reliquia instaura; siguen, a continuación, las visiones de la ciudad, aportadas por anónimos o ilustres visitantes, como la de Aimerico o la de Casto de Médicis, y numerosos comentarios acerca de la historia arquitectónica, política o religiosa de la Compostela de entonces.

\footnotetext{
${ }^{4}$ La primera edición en Afrodisio Aguado es una edición de lujo, magníficamente ilustrada por la pintora rumana María Droc, artista por aquellos años exiliada en la España franquista. En 1993, la Diputación de La Coruña y la editorial Destino publican una hermosa edición del texto de Torrente Ballester, ilustrado con fotografías de Xurxo Lobato y con un prólogo del poeta César Antonio Molina.

${ }^{5}$ La Fundación Gonzalo Torrente Ballester, con el apoyo del Consorcio de Santiago, publicó en 2010, con motivo del centenario del nacimiento del autor, una edición facsimilar de la obra original.
} 
Si Compostela y su ángel, se instala en el Santiago medieval, Santiago de Rosalía retrata la Compostela decimonónica. La obra, que pertenece a la colección, «Ciudades de la Historia» ${ }^{6}$, editada por Planeta en $1989^{7}$, está dividida en doce capítulos; los cuatro primeros, muy breves, contienen información sobre aspectos de tipo urbanístico o costumbrista de la ciudad, aderezados con algunas notas socioeconómicas; en los ocho restantes, el autor se detiene con parsimonia en personajes, reales o ficticios, relacionados con Compostela. En estos últimos, es sencillo observar una clara voluntad literaturizante que revela el esfuerzo del autor, tal vez inevitable, para contrarrestar las restricciones que la editorial y la colección imponen. Por ello, son frecuentes las trasgresiones de las coordenadas espacio-temporales, en las que el contenido del texto traspasa las fronteras físicas de la ciudad, o se desplaza hacia el futuro y hacia el pasado para proporcionar el origen o el resultado de determinados hechos o usos sociales. En otras ocasiones, la introducción de episodios curiosos es lo que quebranta dichos límites editoriales, sin más justificación que la del gusto por contar y entretener ${ }^{8}$. Tal es el caso, por ejemplo, de los comentarios sobre algunas peculiares costumbres compostelanas, perdidas ya en el presente desde el que escribe el autor:

Alguien, tampoco se sabe quién, inventó una especie de observatorios de los que todavía quedan restos. Consistían en un agujero cuadrangular perforado en el suelo de la primera planta y tapado con una especie de trampilla. Se levantaba, con la familia alrededor, y se podía ver al paseante sin ser visto, aunque sí sospechado. Pero las costumbres tienen las ventaja de ser efímeras, y, cuando y han pasado, difícilmente se comprenden. Cuando algún forastero pregunta por la función de aquella especie de tragaluces que aún subsisten en el techo de los soportales y se les explica, no suelen creerlo (1989: 18).

Si a esto añadimos que todo el libro está impregnado con pinceladas del humor irónico característico del autor, de su cultura y su imaginación, el resultado es un texto que contiene, señala Dolores Troncoso, «una muy amplia y amena visión del siglo XIX, en la que Santiago funciona como receptor de la historia política, económica, social y artística de esa etapa de la historia en que la burguesía, con grandes dificultades, llegó al poder» (2004:121-122).

Nada voy a decir, no es este el momento, de los numerosos artículos de prensa escritos por el autor en los que se refiere a esta ciudad, tan vinculada a su biografía, queden aquí sólo nombrados. Me interesa ahora abordar una novela que utiliza como lugar de acción Compostela, que cede su historia, sus mitos y su geografía a la creación ficcional de Torrente Ballester. Estoy aludiendo a Fragmentos de Apocalipsis, novela publicado en 1977 y con la que obtuvo el Premio de la Crítica ${ }^{9}$.

Santiago es ahora, en esta novela, Villasanta de la Estrella. La elección del topónimo resulta harto significativa y, tras él, cualquier lector identifica inequívocamente el centro neurálgico de

\footnotetext{
${ }^{6}$ La Editorial Planeta encomienda para esta misma colección el retrato de otras ciudades a autores de reconocido prestigio; así, por ejemplo, Luis racionero escribe sobre Atenas y Florencia, Madrid se le encarga a Néstor Lujan, Juan Benet se ocupa de Londres y Jesús Ferrero de Pekín.

${ }^{7}$ En la segunda edición, publicada también por Planeta en 1998, se suprimen las ilustraciones de Ester Berenguer que acompañaban el texto de la primera.

${ }^{8}$ Para un detenido análisis de esta obra, puede consultarse el interesante y bien documentado artículo de Dolores Troncoso, publicado en el número 2 de la revista La Tabla redonda. Anuario de estudios torrentinos, dedicado a las obras escritas por Torrente Ballester en las que Santiago es el centro o el escenario.

91977 es también el año en el que Gonzalo Torrente ingresa en la Real Academia Española, siendo apadrinado por otro gran escritor gallego: Camilo José Cela.
} 
Compostela: su catedral, y el culto al Apóstol Santiago. Sin embargo, las referencias a la sociedad real compostelana son muy escasas: se habla de la Universidad; de profesores y de estudiantes, también de curas, pero carecen, en general, de importancia para la historia; constituyen un telón de fondo sobre el que se proyectan otros temas, inventados o reales, pero transformados por la imaginación, y que sostienen la esencia del relato. Santiago está en el ambiente, en el color de sus piedras, en la lluvia, en el sonido de las campanas, en la humedad y la riqueza monumental, pero otra es su historia, sus personajes; otras son las aventuras de los habitantes de Villasanta.

Torrente realiza en esta novela el ejercicio de desvelar al lector el proceso de elaboración recreando en toda su extensión el «taller» del escritor. Así construida, la novela consiste en la escritura por un novelista (cuyo nombre ignoramos, pero que es casi un anciano y muy miope), de un diario de trabajo y sus conversaciones con Lénutchka.

Lénutchka es una profesora de Literatura de la universidad de Leningrado, educada en el formalismo y el marxismo, con quien el narrador entabla relaciones de amistad por carta, y con quien discute los detalles y procedimientos que le ayudan a componer una novela; una novela de la que él mismo es un personaje y cuyo proceso de gestación conocemos a través del diario de trabajo del novelista.

De la relación epistolar entre Lénutchka y el narrador surge el amor, pero la distancia entre ambos resulta ser un obstáculo insalvable, de modo que, para superarlo y poder consumar su amor, el narrador, a petición de la muchacha, la convierte en personaje de la novela que está escribiendo; de este modo, ambos tienen la misma condición, sólo son palabras: «No te olvides de que eres un conjunto de palabras, lo mismo da tú que yo, si te desdoblas somos tú y yo, pero puedes también, a voluntad, ser tú o yo, sin otros límites que los gramaticales» (Fragmentos de Apocalipsis, 16) ${ }^{10}$.

En otro plano, se sitúan los relatos que formarán parte de la novela que escribe el narrador, y las secuencias proféticas escritas por uno de sus personajes, Justo Samaniego, en las que vaticina la invasión de la ciudad por los vikingos y su destrucción apocalíptica.

La técnica empleada en la composición de este discurso novelesco remite al Génesis bíblico, es decir, al mágico poder de creación de la palabra: Villasanta de la Estrella y las gentes que la habitan existen en virtud de que han sido nombradas:

Lo normal es que llueva: una lluvia menuda, azulada, caliente. Desde aquellas alturas se ve la masa gris, inmensidad vacía y silenciosa y nada más. Detrás tienen que estar las campanas: delante los balaustres de piedra; un poco más arriba, el remate redondo de la torre, con su correspondiente veleta [...]. He nombrado la torre, y ahí está. Ahora, si nombro la ciudad, ahí estará también. Entonces digo: catedral, monasterios, iglesias, la universidad, el ayuntamiento, el palacio del arzobispo; y digo: rúas, plazas, travesías [...]; digo columnas, pórticos, bóvedas, ángeles, santos, profetas, volutas, pilastras, pináculos (Fragmentos de Apocalipsis, 16).

Por ello, cuando la novela finaliza, y el narrador empieza a pensar en otra cosa, la ciudad va destruyéndose a cada toque de campana; sobrevive el narrador, amparado por el lenguaje:

\footnotetext{
${ }^{10}$ Todas las citas de la novela pertenecen a la primera edición en Barcelona: Destino, 1977.
} 
La primera campanada sonó al amanecer: cayeron muchos pináculos y todas las veletas [...] Tardó un minuto la segunda [...] se venían abajo las ramas de los magnolios como las torres, y los troncos se desintegraban como la piedra misma. De la catedral, a la tercera campanada, quedaron algunos arcos, que se desmoronaron tres campanadas después. A la salida del sol, Villasanta era un montón humeante de ruinas: el polvillo, en el día claro, se levantaba hasta cubrir el cielo, y, a cada nueva campanada, se movía en remolinos espesos de tendencia ascensional (Fragmentos de Apocalipsis, 392) ${ }^{11}$.

La personalidad de los protagonistas es, en algunos casos, tan peculiar que podría rayar en lo fabuloso: citaré, como muestra, al bonzo Ferreiro y sus extraños viajes astrales; al ciego Marcelo y sus obsesiones amorosas, auténtica encarnación del mal; al arzobispo que vuela y que juega al mus con el grupo de anarquistas en la torre de la catedral (donde vive Ramiro, el sastre) y, entre los anarquistas, a Pablo y su concepción cíclica y repetitiva de la Historia, razón por la cual sueña con la posibilidad de desplazarse por el universo hacia el pasado, para impedir el asesinato de Marat y, con ello, el advenimiento del imperio napoleónico, a cuyo famoso código atribuye Pablo todas las desdichas de la sociedad actual. Cada uno de estos personajes configura un núcleo temático diferente que se articula en tramas paralelas, aunque de un modo u otro todas convergen en el recinto de la catedral de Villasanta.

Si la catedral de Santiago custodia los restos del Apóstol, la de Villasanta está construida sobre un laberinto que guarda los restos de Doña Esclaramunda, hija del obispo Sisnando, de la cual el rey vikingo Olaf estaba enamorado.

Dicen que hay huesos en una arqueta, y que son de un apóstol. ¡Bah! Prefiero que lo sean de Esclaramunda Bendaña, un nombre que acaba de ocurrírseme, así, de pronto, a causa de ciertas relaciones, y que me gusta. Una vez inventado habrá que justificar con una historia su situación de privilegio, porque no es lo corriente que los huesos de una muchacha que no fue santa reposen en un lugar tan distinguido (Fragmentos de Apocalipsis, 19).

Con el objeto de evitar el rapto de su hija, el obispo Sisnando la mata y la entierra en la catedral, en el centro de un laberinto de piedra formado por letras que componen una frase de amor. Pero este secreto fue sabiamente encubierto y enmascarado en el mito de un santo de la Iglesia cristiana, al que en Villasanta se venera. El secreto está recogido en un manuscrito, Los Comentarios al Apocalipsis del Beato de Liébana, que posee don Procopio, canónigo fabriquero de la catedral. Dicho manuscrito contiene además la profecía del rey Olaf, según la cual el vikingo volverá después de mil años a Villasanta y la destruirá, vengando de ese modo la ofensa de Sisnando, que le privó de su amor.

Todas estas historias y muchas otras, que aparecen diseminadas y fragmentadas a lo largo de la obra, constituyen las notas del cuaderno de trabajo del escritor que intenta escribir una novela -esa novela-, al mismo tiempo que discute su estructura y los detalles con Lénutchka, la mujer de quien el escritor termina enamorándose.

Dejando a un lado la bellísima historia de amor entre el escritor y Lénutchka, en los retazos de novela que escribe, el lector reconoce, sin dificultad, la desmitificación a la que somete Torrente al

\footnotetext{
${ }^{11}$ Recordemos ahora aquella página inicial de Compostela y su ángel: «Compostela se hace en torno a la campana... Cuando la niebla sumerge a la ciudad, todo vuelve al estado primitivo e informe y no quedan sino la niebla y las campanas». En otro lugar, Torrente señala que en esta descripción ya está contenido Fragmentos de Apocalipis (Carmen Becerra, 1990: 204).
} 
mito del Apóstol Santiago, esencia de Compostela, pero también de Villasanta de la Estrella. Tal desmitificación, operación, por otra parte, muy frecuente en la literatura del autor, obtiene probablemente uno de sus fundamentos en las prolijas y sesudas discusiones acerca de la identidad real de los restos venerados en la catedral; es decir, en la discutida y polémica posible suplantación de Prisciliano, obispo hispánico del siglo IV, condenado y ejecutado en Tréveris por un crimen de magia, que fue enterrado en Galicia, tierra en la que la secta priscilianista tuvo una ferviente acogida entre el pueblo. En Fragmentos, la historia oficial se opone a la verdad poética de Villasanta de la Estrella ${ }^{12}$. Gonzalo Torrente, buen conocedor de la historia de la ciudad y de sus orígenes, convierte el sepulcro de Doña Esclaramunda en el evidente paralelo de la tumba del Apóstol, sin duda como ilustración del embuste construido en torno al descubrimiento del sepulcro del santo que el propio autor, en Compostela y su ángel, califica de invención, de feliz receta para solucionar una necesidad histórica particular $^{13}$.

En una de las primeras páginas de Fragmentos, leemos:

Las viejas de mi tierra, en otros tiempos, obraban, con retazos, mantas multicolores que llaman farrapeiras, como tejidos de harapos que eran. Eso, harapos, es lo mío, harapos que fueron telas suntuosas y brillantes, rasgadas ahora y hasta podridas antes de alcanzar su forma. Cuelgan o se amontonan, si están inertes; y si las mueve un viento, y las alumbra la luz, ellas solas se organizan en grupos caprichosos, fuera de cualquier lógica y de cualquier razón (Fragmentos de Apocalipsis, 14).

Así conformada, con harapos, de manera fragmentaria, como revela su narrador principal, la novela demanda del lector atento una lectura competente, pero, a pesar de su compleja estructura, conjuga con habilidad el juego paródico con un magistral despliegue en el arte de contar.

La catedral de Villasanta ocupa el centro espacial de la novela: es el lugar donde se desarrollan algunas de las historias contadas y desde el que se irradia la aventura de los personajes. El laberinto de la catedral no sólo es el perfecto refugio donde yace el cuerpo de la bella Esclaramunda, representa además el principio constructivo que sustenta la novela y que se proyecta a todo lo demás: a la ciudad con el trazado sinuoso de sus calles, a los personajes creados, duplicados, abandonados a favor de otros; a la conciencia «enmarañada» del narrador que llega a presentarse a sí mismo como agente secreto conocido en el mundo de los agentes secretos como «el maestro de las pistas que se bifurcan» ${ }^{14}$ y que construye un laberinto de palabras para refugiarse en él y ocultarse de los que le persiguen: «El

12 A juicio del escritor Germán Sierra: «Fragmentos es el texto más adecuado a Compostela: el que mejor resume su personalidad barroca, juguetona, irreal e irremediablemente...provinciana [...]. Fragmentos traslada al lector a una ciudad imaginaria que se burla sin piedad de su modelo real, de sus pretensiones históricas y sus grandilocuencias intelectuales y políticas» (2004: 20).

13 «Había una absoluta imposibilidad física de que el Santo Sepulcro, cautivo de mahometanos, pudiera canalizar el entusiasmo religioso de aquellos tiempos y el sepulcro de Pedro era demasiado conocido para que pudiera atraer a las muchedumbres. En cambio, en el de Santiago, ignorado casi ochocientos años, descubierto en el momento oportuno, en que Europa se dispone a resistir las calamidades milenarias, coincidían, de una parte, la importancia suficiente para constituir un acontecimiento universal, puesto que Santiago, con Pedro y Juan, contaba entre los preferidos del Señor; por la otra, la dosis necesaria de novedad para que los cristianos se sintieran atraídos». Gonzalo Torrente Ballester, «La invención del sepulcro» en Compostela y su ángel, p. 36.

${ }^{14}$ Nombre que recuerda, sin duda, a «El jardín de los senderos que se bifurcan», título de uno de los relatos que contiene la obra Ficciones, de Jorge Luis Borges, publicada en 1944. 
cerco, sin embargo, que me han puesto unos y otros, es más amenazador que en otras ocasiones, y por eso me he refugiado en el interior de esta novela, mero conjunto de palabras, como el gusano se esconde en el ovillo que él mismo fabrica» (Fragmentos de Apocalipsis, 42)

En fin, una estructura caótica y ordenada a la vez; aparentemente confusa y, sin embargo, perfectamente articulada. Es fácil apreciar además un rasgo, en esta novela especialmente relevante, que caracteriza la escritura de su autor: me refiero a la mezcla, y a veces fusión, de su vertiente críticoteórica y su labor imaginativa. Torrente no ha dejado nunca de reflexionar sobre el hecho literario, como acreditan sus ensayos, artículos, prólogos en obras propias o ajenas, diarios de trabajo, conferencias, etc., pero también sus ficciones y Fragmentos de Apocalipsis es una buena muestra de ello:

Descarto, por supuesto, cualquier salida realista, de esas que conducen a ficciones sociológicas, necesitadas de apoyos algo más convincentes que los míos, porque puestos en esta tesitura, ¿hay quién se trague lo de un arzobispo ${ }^{15}$ que se escapa volando de su palacio para jugar al mus con una trinca de anarquistas? La verosimilitud de semejante situación sólo se adquiere si la insertamos en una gran estructura de ambiciosas significaciones, símbolo cósmico o alegoría moral de impresionante catadura (Fragmentos de Apocalipsis, 78).

Una vez más, el autor gallego, partiendo de la realidad, ejecuta sobre la misma una labor de transformación, utilizando el inmenso caudal de sus conocimientos y de su fértil imaginación y fantasía, pero el resultado posee más de una clave de lectura, sólo es preciso para entenderlo en toda su riqueza traspasar el nivel de la apariencia lúdica, ver detrás del humor la seriedad del humorista.

En 1992 Gonzalo Torrente publica La muerte del decano ${ }^{16}$. Se trata de una novela que se inscribe en el género policíaco, «dentro de la corriente de novelas de juego intelectual, siguiendo la tradición anglosajona de G. K. Chesterton y su detective amateur Padre Brown», sostiene José F Colmeiro (2004:135-150). La muerte del decano pertenece además a la corriente, también anglosajona, de las llamadas «novelas de campus», que fue inaugurada en España por la obra, Todas las almas (1989), de Javier Marías.

El autor utiliza este molde genérico para cuestionar los grandes relatos legitimadores de la realidad -la Historia es uno de ellos - construyendo al personaje del Decano, catedrático de Historia y paradójico ejemplo de tal cuestionamiento, cuya concepción de esa disciplina está basada en el reconocimiento expreso de su inherente inestabilidad y subjetividad y, en consecuencia, de su dudosa verdad; por consiguiente, la novela contiene mucho más que un posible crimen o un probable suicidio sin resolver, como afirma José F. Colmeiro:

El acto inmolatorio del Decano, su renuncia a la Historia y el reconocimiento de su propia inutilidad, y su conversión en autor literario, marcan el fin de la Historia como certeza absoluta e incontestable. Por ello, su muerte repetidamente anunciada es una simbólica acta de defunción metaficcional donde Torrente escribe la posmoderna crónica anunciada del fin de los grandes relatos y las certezas absolutas (2004: 149).

\footnotetext{
${ }^{15}$ Muy probablemente la fuente de inspiración para este singular arzobispo se halle en la figura de Pedro Muñiz, hombre aficionado a las letras, escudriñador de misterios, gran lector y discutidor, que vive a principios del siglo XIII. En su tiempo, la catedral compostelana fue solemnemente consagrada. Se le atribuyó fama de nigromante. Se decía que volaba desde Roma a Santiago al rezo de maitines. Está enterrado en la catedral de Santiago, al pie del Pórtico de la Gloria

16 Todas las citas de la novela corresponden a la primera edición en Barcelona: Planeta, 1992.
} 
La novela se sitúa en los primeros años de la posguerra española. Los personajes se mueven en un ambiente intelectual de mediocridad, de pobreza moral colectiva, de resignación política, de ausencia de estímulos para el pensamiento y la investigación, sometidos a la censura. Espacialmente hablando, la mayor parte de la acción discurre en una innominada ciudad que sin duda remite a Santiago de Compostela ${ }^{17}$. Se trata de una pequeña y lluviosa ciudad de provincias del norte peninsular, religiosa y universitaria y que depende jurídicamente de La Coruña ${ }^{18}$, características inequívocas, todas ellas, de la Compostela de la primera mitad del siglo XX.

En la calle orvallaba, un orvallo frío que le estremeció hasta los huesos, un momento [...] Echó a andar, el paraguas abierto, que no le cubría de la lluvia la punta de los dedos. A la derecha le quedaba la facultad de Medicina ${ }^{19}$, con grupos de estudiantes a la puerta, entrantes o salientes de alguna clase temprana (La muerte del Decano, 90-91).

Aparte de algunos lugares con nombre propio, como la catedral, la taberna Ramallo o el Hotel España, entre otros, se mencionan los edificios de la Universidad, los colegios mayores, los claustros, las rúas, los soportales y las calles mojadas, como impreciso marco de la acción. La novela obvia la descripción de la ciudad, generando con su ausencia un territorio dibujado con el color de la ciudad de piedra, gris como el ambiente, bajo una tenue luz y una persistente lluvia:

Había cesado el viento, y la lluvia que caía era fina y mansa. Abrió el paraguas y se echó a andar [...]. Llegó a la rúa y se metió bajo los soportales cuando pasaban dos chicas, estudiantes, metidas en sus impermeables transparentes, con los paraguas cerrados [...]. Deambuló un buen rato, por esta rúa y por la otra, a veces se detenía ante un rincón o ante el reflejo de las losas mojadas [...]. Cuando dieron las nueve en el reloj de la catedral, apuró el paso y fue hasta la taberna Ramallo (La muerte del Decano, 24).

Esta ausencia de datos concretos sobre el marco espacial de la acción contribuye a la generación de un ambiente y refuerza, según Colmeiro, “el escepticismo y la incertidumbre sobre la que se construye todo el edificio de la novela" (2004:140).

Así pues, Santiago de Compostela se erige, una y otra vez, en un espacio valioso, genuino y fantástico para los mundos de ficción creados por la pluma del escritor gallego. La ciudad milenaria, en el marco de una Galicia mítica, se convierte en el refugio de la emoción y en el móvil de su imaginación. No sorprenden, por ello, confesiones del autor como la que sigue:

No quiero asegurar que todo lo que ha servido de fundamento y de materia a mi escritura me venga de Compostela, pero sí la mayor parte, y, desde luego, a esta ciudad debo determinadas experiencias que me ayudaron a fortalecer o a corregir las fundamentales que me permiten vivir y escribir [...]. Compostela no es cualquier parte, y un amigo mío me decía, al inicio de mis amores con ella, que estas piedras tenían la virtud de transformarlo todo, hasta los siete pecados capitales. (Compostela y su ángel, 13-14).

En 1916, Ramón M. ${ }^{a}$ del Valle-Inclán describía, en La lámpara maravillosa, la ciudad de Compostela:

\footnotetext{
${ }^{17}$ Recordemos que Gonzalo Torrente gana por concurso-oposición la plaza de profesor Auxiliar de Historia Antigua en la Facultad de Filosofía y Letras de la Universidad de Santiago de Compostela, unos meses antes del comienzo de la Guerra Civil española.

${ }^{18}$ Este dato, la dependencia jurídica de La Coruña, es conocido por el lector casi al final de la novela.

19 Todavía hoy la única Facultad de Medicina de la Comunidad Autónoma gallega está en Santiago. Medicina es una de las Facultades más antiguas de la Universidad Compostelana.
} 


\begin{abstract}
De todas las rancias ciudades españolas, la que parece inmovilizada en un sueño de granito, inmutable y eterno, es Santiago de Compostela... En esta ciudad petrificada huye la idea del Tiempo. No parece antigua, sino eterna... Compostela, inmovilizada en el éxtasis de los peregrinos, junta todas sus piedras en una sola evocación, y la cadena de siglos tuvo siempre en sus ecos la misma resonancia. Allí las horas son una misma hora, eternamente repetida bajo un cielo lluvioso. ${ }^{20}$
\end{abstract}

Por el contrario, la visión de Torrente Ballester parece bien distinta:

\footnotetext{
Compostela se mueve perpetuamente en torno a una meta de perfección inalcanzable... La eternidad de Compostela se parece a la eternidad del tiempo, y, como el tiempo, es mutable, si bien tan lentamente que a veces una sola generación sólo alcanza a percibir las variaciones superficiales del color de las piedras (Compostela y su ángel, 234.).
}

Así pues, frente a la eternidad como inmutabilidad de Valle-Inclán, para Torrente Santiago está inmovilizado en la eternidad; su tiempo es lento, sí, pero su decurso no tiene fin. Sólo hemos de recordar sus palabras: «el ser de Compostela es este hacerse y deshacerse en juego interminable».

\title{
Referencias bibliográficas
}

BECERRA, Carmen (2005): La historia en la ficción. La narrativa de Gonzalo Torrente Ballester. Madrid, Ediciones del Orto.

- (1990): Guardo la voz, cedo la palabra. Conversaciones con Gonzalo Torrente Ballester. Barcelona, Anthropos.

Colmeiro, José F. (2004): «Historia y metaficción en La muerte del decano de Torrente Ballester: Crónica posmoderna de una muerte anunciada», La tabla Redonda, 2. Vigo, Universidad de Vigo, pp. 135-150.

LOUREIRO, Ángel (1997): «Torrente Ballester, novelista posmoderno”, en Ángel ABUín, Carmen BECERRA y Manuel Á. CANDELAS, eds., La creación literaria de Gonzalo Torrente Ballester. Vigo, Tambre, pp. 61-76.

SIERRA, Germán (2004): «Villasanta desde Compostela», La Tabla Redonda, 2. Vigo, Universidad de Vigo, pp. 19-26.

Torrente Ballester, Gonzalo (1977): Fragmentos de Apocalipsis. Barcelona, Destino. (1980): «La Biblioteca (1939-1942)», La Universidad de Santiago. Santiago de Compostela,

Servicio de Publicaciones de la Universidad de Santiago.

_ (1983): Dafne y ensueños. Barcelona, Destino, Colección Áncora y Delfín.

- (1984): Compostela y su ángel. Barcelona, Destino.

- (1989): Santiago de Rosalía de Castro. Barcelona, Planeta. (1992): La muerte del Decano. Barcelona, Planeta.

Troncoso Durán, Dolores (2004): «Santiago de Rosalía de castro», La Tabla Redonda, 2. Vigo, Universidad de Vigo, pp. 113-122.

\footnotetext{
${ }^{20}$ Cito por la tercera edición en Austral, Espasa Calpe, 1974, pp. 95-97.
} 